DOI: 10.20472/IAC.2018.044.002

UTKU ALTUNOZ

sinop university, Turkey

\title{
DOES HERD BEHAVIOUR EXIST IN TURKISH STOCK MARKETS? THE CASE OF BORSA ISTANBUL
}

\begin{abstract}
:
Herd describes how individuals in a group can act collectively without centralized direction. The herd behavior on stock markets implies that investors ignore their own ideas in stock trading decisions and trade in the direction of the market. It is important to detect the effect of herding behavior in markets to assess the validity of rational asset pricing models and diversification opportunities. This paper, the validity of herding has been researched at Borsa Istanbul by considering two different models developed by Christie and Huang (1995) and Chang, Cheng, and Khorana (2000). Research data consists of daily logarithmic stock returns for the period of 1998 - 2016. Study has been diversified by dividing the period into two sub-periods, 1998-2005 and 2006-2016. According to obtained results, the direction that herding behavior effect has been felt intensively at the first sub-period in rising market conditions. The effect has fallen at the second sub-period.
\end{abstract}

\section{Keywords:}

: Herding Behavior, Diversification, Christie and Huang (1995) Model, Chang, Cheng, and Khorana (2000) Model.

JEL Classification: C12, C13, G14 


\section{Introducing}

Herd behavior describes how individuals in a group can act collectively without centralized direction. The herd behavior on stock markets implies that investors ignore their own ideas in stock trading decisions and trade in the direction of the market. It is important to detect the effect of herding behavior in markets to assess the validity of rational asset pricing models and diversification opportunities. Christie and Huang (1995) methods is One of the method developed to measure the herd behavior in stock market. The study by Christie and Huang (1995) is an important reference source for many subsequent studies. According to Christie and Huang, herd behavior means a relates to instances in which individuals gravitate to the same or similar investments based almost solely on the fact that many others are investing in those stocks. The existence of herd behavior is one usually expressed statement for the volatility of stock returns (Christie and Huang, 1995, p 31).

Investors are the part of herd if they are conscious of and influenced by the actions of others' (Bikhchandani and Sharma, 2001, p 280).People who interest in the economy are focused on the behavioral effect on stock prices. According to asset pricing models, the potential effect on their return and risk are the characteristics the consequences of models.

Recent years, majority of economist has focused on the herding among market participants in the stock markets. The empirical researches have generally focused on the market of the developing and developed countries.

This paperaims to give the reader an understanding of the concept of herd behavior and its implications for the financial market.In accordance with this purpose, this paper investigates the existence of herd behavior throughChristie and Huang (1995), Chang, Cheng and Khorana (2000) methodology.

\section{Theorical Backgroundof HerdBehavior}

Two main opinions of investment behavior of market participant in financial markets are mostly regarded. Those are the traditional and the behavioral finance views.

In the traditional framework for finance the efficient market hypothesis (EMH) and its implications is a major cornerstone. In fact, the field of academic finance was largely built based on the EMH (Shleifer, 2000, p. 1).

\section{Approaches of the Measuring of the Herd Behavior in Capital Markets}

There are some improved methods of measuring herd behavior in capital markets. Among these methods, Lakonishok, Scleifer and Vishny (1992), Christie and Huang (1995), Chang, Cheng and Khorana (2000) and Hwang and Salmon (2004) have found the most place in the literature. Hwang and Salmon (2004) developed a new method of measuring herd behavior regarding previous studies. Unlike traditional herd behaviors measurement method, the study of Hwang and Salmon can distinguish true and false herd behavior. Hwang and Salmon don't accept to the assumptions of 
efficiency market hypothesis. They agree that herd behavior exists in the financial marketsand herd behavior pushes asset prices away from the equilibrium proposed by traditional financial theory, such as the Capital Assets Pricing Model, leading to prices that no longer reflect the true value of companies. It can be said that the foundation of Hwang and Salmon's work in 2004 rests on Christie and Huang's work in 1995 and Chang et al. in 2000.

Christie and Huang (1995) and Chang et al. (2000) claim that investors show a tendency to herd behaviors during the periods of high volatility in capital markets.

In case of Herd behavior, the returns of individual stock converge towards the returns on the aggregate market - market index. Thus, herd behavior problem results in a smaller difference between the returns on the individual stock and the market index. CSSD term is described by Christie and Huang (1995) as equation (1) below:

$\operatorname{CSSD}_{t}=\sqrt{\frac{\sum_{i=1}^{N_{t}}\left(R_{i, t}-R_{m, t}\right)^{2}}{N_{t}-1}}$

In addition, CSAD is suggested and estimated the following regression in equation (2) below by Chang at al. (2000)

$C S A D_{t}=\frac{\sum_{i=1}^{N}\left\lfloor R_{i t}-R_{m t}\right\rfloor}{N}$

In equation (1) and (2), respectively $R_{i, t}$ represents the return of stock i during period t; $R_{m, t}$ shows the return of market index over the period $\mathrm{t} ; N_{t}$ is the number of stock listed in equity market during period t. Both these methods are showed by equation (1) and equation (2) use total risk. Analaysis of Christie and Huang (1995) and Chang, Cheng and Khorana (2000) Will be explained in detail in the econometric analysis section.Another way is to determine the systematic risk only to calculate the crosssectional dispersion and to suppose that herding occurs because of sentiment rather than market or firm level fundamentals (Hwang \& Salmon, 2004).According to Hwang and Salmon (2004), in the presence of market behavior, the following relationship exists in the equilibrium model:

$\frac{E_{t}^{b}\left(r_{i t}\right)}{E_{t}\left(r_{m t}\right)}=\beta_{i m t}^{b}=\beta_{i m t}^{b}-h_{m t}\left(\beta_{i m t}-1\right)$

In equation (3) $E_{t}^{b}\left(r_{i t}\right)$ represents the biased short-run conditional expectation on the market excess return at time t. The unnoticed herdingsignhmt is the parameter supposed to be well-proportioned to the deviation of the individual true beta from market beta. The cross-sectional variation of $\beta i m t b$ is; (Güvercin, 2016:27).

$S t d_{c}=\left(\beta_{i m t}^{b}\right)=S t d_{c}\left(\beta_{i m t}\right)\left(1-h_{m t}\right)(4)$

When equation (4) is taken logarithms, it can be attained the equation (5) below; 
$\ln \left[\operatorname{Std}_{c}\left(\beta_{i m t}^{b}\right)\right]=\ln \left[s t d_{c}\left(\beta_{i m t}\right)\right]+\ln \left(1-h_{m t}\right)(5)$

equation (5) can be re written like equation (6) as below:

$\ln \left[\operatorname{Std}_{c}\left(\beta_{i m t}^{b}\right)\right]=\mu_{t}+H_{m t}+v_{m t}$

In equation (6), $\mu_{t}=\ln \left[S t d_{c}\left(\beta_{i m t}^{b}\right)\right]$ suppose constant in the short run. In addition, $H_{m t}=\ln \left(1-h_{m t}\right)$.

According to Hwang and Salmon (2004), asset betas are constant over the time and the variation in beta with the time is observed due to herd behavior. So that they allow $h_{m t}$, to follow a dynamic process AR(1), and the system becomes:

$\ln \left[\operatorname{Srd}_{c}\left(\beta_{i m t}^{b}\right]=\mu_{t}+H_{m t}+v_{m t} a_{n d H_{m t}}=\emptyset_{m} H_{m t-1}+\eta_{m t}(7)\right.$

Where double ECT (error correction term) $v_{m t} \sim i i d\left(0, \partial_{m v}^{2}\right)$ and $\eta_{m t} \sim \operatorname{iid}\left(0, \partial_{m v}^{2}\right)$, respectively.

$\operatorname{std}(\beta)_{t}=\sqrt{\frac{\sum_{i=1}^{n}\left(\text { beta }_{i t}-\overline{\overline{\left(b e t a_{t}\right)^{2}}}\right.}{n-1}}(8)$

Equation 6 (Model 1) ismodified to involve two market fundamentals for robustness. If Hmt becomes insignificant after the inclusion of market volatility and returns, then changes in $S t d c(\beta i m t b)$ is explained by market fundamentals rather than by herding and hence there will be no evidence of herding(Güvercin,2016:28).

$\ln \left[s t d_{c}\left(\beta_{i m t}^{b}\right)\right]=\mu_{m}+H_{m t}+\theta_{c 1} \ln \sigma_{m t}+\theta_{c 2} r_{m t}+v_{m t}$

wherelnomt and rmtrepresent log market volatility and return in time t. While equations [6] shows the base model (model 1), equations in [9] indicate the robust model (Model 2)

\section{Literature Review}

Ohlson (2010) used the method of measurement of herd behavior based on horizontal cross-sectional variability in the Stockholm Stock Exchange over the periods 19982009 and detected herd behavior in the Stockholm Stock Exchange.

Demirer, Kutan and Chen (2010) used Christie and Huang's (1995) method to examine herd behavior in Taiwan's capital market as a developing country.As a result of the study, herd behavior could not be detected in the Taiwanese capital markets.

My and Truong (2011) tested the herd behavior in Capital Markets in Vietnam where is one of the East country. Different model specifications and lots for market periods They have reached the conclusion that herd behavior is valid covered the periods 2002-2007.

Kapusuzoğlu (2011) tested the herd behavior and volatility of stock rate of return by Christie and Huang (1995) with Chang et al. (2000). As a result of study, he obtained 
that herding behaviour is valid in Istanbul stock exchange (ISE) National 100 index and a nonlinear relationship exists between them.

Kayalıdere (2012) examined the herd behavior effect in Borsa Istanbul. Findings are in the direction that herding behavior effect has been felt intensively at the first subperiod in rising market conditions. The effect has fallen at the second sub-period.

Solakoglu and Demir (2014) investigated the herding by using BIST 30 and Second National Market (SNM) data. They find sentiment herding only in SNM, where the investors are mostly domestic investors.

Güvercin (2016) examined the herd behavior for Egypt Saudi stock capital markets over the period 2002-20014 by using Hwang and Salmon (2004) methodology. At the end of study, Güvercin has attained the result that herding is valid only Egypt. And also, it was appealed in the study that Egypt, mortgage crisis and Egyptian military takeover for herd behavior but not oil return volatility has no impact.

\section{Data Set and Methodology}

In this paper, the impact of herd behavior based on BIST 100, Financial, Industrial and Services Indexes in the Borsa İstanbul as explored using daily logarithmic implications of the shares over the period 1998-2016.In addition, during the 1998-2016 period, the 12 most liquid shares traded on a minimum of 5,000 lots on all trading days are determined and analyzed the herd behavior effect on the most liquid shares. For the empirical model, study of Kayalıdere (2012) ,Christieand Huang (1995) and Chang, Cheng and Khorana (2000) methodology will be used. Christie and Huang (1995) claim that during large price movements, individual shareholders might come to pass their knowledge over of stock prices and instead, base trade decisions on the behavior of the market. If investors Show herd behavior, individual stockreturns will tend to be clustered closely to the return ofthe market. As indicated in equation (1), Christie and Huang (1995) use the cross-sectional standard deviation (CSSD) of individualstock returns as a measure of the degree of clustering around the market aggregate.

$$
\operatorname{CSSD}_{t}=\sqrt{\frac{\sum_{i=1}^{N_{t}}\left(R_{i, t}-R_{m, t}\right)^{2}}{N_{t}-1}}(10)
$$

In addition, CSAD is suggested and estimated the following regression in equation (11) below by Chang at al. (2000)

$C S A D_{t}=\frac{\sum_{i=1}^{N}\left\lfloor R_{i t}-R_{m t}\right\rfloor}{N}$

In equation (10) and (11), respectively $R_{i, t}$ represents the return of stock $\mathrm{i}$ during period t; $R_{m, t}$ shows the return of market index over the period $\mathrm{t} ; N_{t}$ is the number of stock listed in equity market during period $t$.

To test for nonlinearity Chang, Cheng and Khorana (2000) estimate the following regression: 
$\operatorname{CSAD}_{t}=\alpha+\gamma_{1}\left|R_{m t}\right|+\gamma_{2}\left(R_{m t}\right)^{2}+e_{t}(12)$

It is expected that $x$ will be positive under the assumption of rational asset pricing. In addition, $y$ should be zero, while the risk of share repurchases reflects the effect on the cross-sectional absolute deviation(CSAD).

It is expected that the coefficient of the nonlinear terms $\gamma_{2}$ will be negative when the herding behavior is existing; In such a case, it could mean a decrease in the CSAD after a certain market movement or even a decline in the case where the absolute market introduction is large enough. The positive y value causes market movements to increase stock returns more than rational pricing.

Chang, Cheng and Khorana (2000) estimate two more models because of the possibility that the degree of organization may be asymmetric in up and down markets and it is formulized as equation(11) and (12 ) below:

$C S A D_{t}^{U P}=\alpha+\gamma_{1}^{U P} R_{m t}^{Y P}+\gamma_{2}^{U P}\left(R_{m t}^{U P}\right)^{2}+e_{t}(13)$

And

$C S A D_{t}^{D O W N}=\alpha+\gamma_{1}^{D O W N}\left|R_{m t}^{D O W N}\right|+\gamma_{2}^{D O W N}\left(R_{m t}^{D O W N}\right)^{2}+e_{t}(14)$

In eqution (13) and (14), $R_{m t}^{U P}$ represents the equally-weighted average returnof the $\mathrm{N}$ stocks available on day $\mathrm{t}$ when this return is positive; $\left|R_{m t}^{D O W N}\right|$ is the absolute value of the equally-weighted average return of the $\mathrm{N}$ stocks available on day $\mathrm{t}$ when this return is negative; $C S A D_{t}^{U P}$ is the $C S A D_{t}$ for the day t where $R_{m t}$ is positive; $C S A D_{t}^{D O W N}$ is the $C S A D_{t}$ for the day twhere $R_{m t}$ is negative.

\subsection{Findings}

Table 1: BIST 100 Index Herd Findings

\begin{tabular}{|c|l|l|l|l|l|}
\hline \multicolumn{7}{|c|}{ BORSA ISTANBUL 100 INDEX 1998-2016 } \\
\hline MODEL & $\alpha$ & $\gamma_{1}$ & $\gamma_{2}$ & F Statistic & $R^{2}$ \\
\hline 1 & $0.0174(0.00)$ & $0.3900(0.00)$ & $-0.890(0.00)$ & $411.143(0.00)$ & 0.412 \\
\hline 2 & $0.0143(0.00)$ & $0.3450(0.00)$ & $-1.466(0.00)$ & $341.246(0.00)$ & 0.312 \\
\hline 3 & $0.0185(0.00)$ & $0.3321(0.00)$ & $-0.288(0.00)$ & $653.125(0.00)$ & 0.171 \\
\hline 4 & $0.0169(0.00)$ & $0.2417(0.00)$ & $0.275(0.00)$ & $623.111(0.00)$ & 0.142 \\
\hline 5 & $0.0176(0.00)$ & $0.3021(0.00)$ & $0.214(0.00)$ & $411.754(0.00)$ & 0.156 \\
\hline & & $1 . T E R M(1998-2005)$ & & \\
\hline 1 & $0.0119(0.00)$ & $0.3146(0.00)$ & $-0.6114(0.00)$ & $472.143(0.00)$ & 0.34 \\
\hline 2 & $0.0140(0.00)$ & $0.3182(0.00)$ & $-0.924(0.00)$ & $436.154(0.00)$ & 0.27 \\
\hline 3 & $0.0209(0.00)$ & $0.2177(0.00)$ & $-0.8718(0.00)$ & $613.122(0.00)$ & 0.29 \\
\hline
\end{tabular}




\begin{tabular}{|c|l|l|l|l|l|}
\hline 4 & $0.0473(0.00)$ & $0.2081(0.00)$ & $0.0132(0.00)$ & $510.412(0.00)$ & 0.26 \\
\hline 5 & $0.05312(0.00)$ & $0.0174(0.00)$ & $0.0412(0.00)$ & $500.134(0.00)$ & 0.22 \\
\hline \multicolumn{7}{|c|}{ 2.TERM (2006-2016) } \\
\hline 2 & $0.0417(0.00)$ & $0.0188(0.00)$ & $0.421(0.00)$ & $341.551(0.00)$ & 0.18 \\
\hline 3 & $0.05312(0.00)$ & $0.0185(0.00)$ & $0.154(0.00)$ & $299.098(0.00)$ & 0.16 \\
\hline 4 & $0.0188(0.00)$ & $0.3012(0.00)$ & $0.0071(0.00)$ & $245.176(0.00)$ & 0.24 \\
\hline 5 & $0.0187(0.00)$ & $0.2177(0.00)$ & $0.0043(0.00)$ & $241.776(0.00)$ & 0.21 \\
\hline
\end{tabular}

When we look at the findings of herd behavior in BIST 100, in terms of the Christie and Huang model, no significant result regarding the existence of the herd effect in neither of the first and second periods is reached for the model (10) and (11).

This is the case with the literature compatible. Chang, Cheng and Khorana model indicates the presence of herd behavior in term 1.It is understood from table 1 that there is no herd effect over the period 2006-2016 (Term 2).

When Negative and statistically significant $\gamma_{2}$ parameters are modeled in the first term, It can be said that the effect of herd behavior on the rising markets is stronger. $F$ statistics of all models were found significant in all periods.For the CCK model, in horizontal market conditions where $R_{m t}$ is zero, the coefficient a represents the average level of return spread. Under these conditions, all equations are estimated positive and statistically significant.

In the CCK model, the coefficient $\alpha$ indicates the level of average return spread in horizontal market conditions where $R_{m, t}$ is zero. And, the coefficient $\alpha$ is positive and statistically significant in all equations.

Table 2: BIST Financial Index Herd Findings

\begin{tabular}{|c|l|l|l|l|l|}
\hline \multicolumn{7}{|c|}{ BORSA iSTANBUL 100 Financial Index 1998-2016 } \\
\hline MODEL & $\alpha$ & $\gamma_{1}$ & $\gamma_{2}$ & F Statistic & $R^{2}$ \\
\hline 1 & $0.0165(0.00)$ & $0.0188(0.00)$ & $-0.890(0.00)$ & $411.143(0.00)$ & 0.412 \\
\hline 2 & $0.0155(0.00)$ & $0.0196(0.00)$ & $-1.412(0.00)$ & $341.246(0.00)$ & 0.312 \\
\hline 3 & $0.0196(0.00)$ & $0.0188(0.00)$ & $-0.645(0.00)$ & $653.125(0.00)$ & 0.171 \\
\hline 4 & $0.0188(0.00)$ & $0.0185(0.00)$ & $0.213(0.00)$ & $623.111(0.00)$ & 0.142 \\
\hline 5 & $0.0187(0.00)$ & $0.0197(0.00)$ & $0.156(0.00)$ & $411.754(0.00)$ & 0.156 \\
\hline \multicolumn{7}{|c|}{ 1.TERM (1998-2005) } \\
\hline
\end{tabular}




\begin{tabular}{|l|l|l|l|l|l|}
\hline 1 & $0.0196(0.00)$ & $0.2166(0.00)$ & $-0.6114(0.00)$ & $561.143(0.00)$ & 0.34 \\
\hline 2 & $0.0188(0.00)$ & $0.3012(0.00)$ & $-0.924(0.00)$ & $312.154(0.00)$ & 0.27 \\
\hline 3 & $0.0190(0.00)$ & $0.2177(0.00)$ & $-0.8718(0.00)$ & $564.122(0.00)$ & 0.29 \\
\hline 4 & $0.0417(0.00)$ & $0.2091(0.00)$ & $0.0132(0.00)$ & $411.412(0.00)$ & 0.26 \\
\hline 5 & $0.05312(0.00)$ & $0.0198(0.00)$ & $0.0412(0.00)$ & $500.134(0.00)$ & 0.22 \\
\hline \multicolumn{7}{|l|}{ 2.TERM (2006-2016) } \\
\hline 1 & $0.0417(0.00)$ & $0.0188(0.00)$ & $0.421(0.00)$ & $341.551(0.00)$ & 0.18 \\
\hline 2 & $0.05312(0.00)$ & $0.0185(0.00)$ & $0.154(0.00)$ & $299.098(0.00)$ & 0.16 \\
\hline 3 & $0.0196(0.00)$ & $0.0197(0.00)$ & $0.0012(0.00)$ & $341.899(0.00)$ & 0.21 \\
\hline 4 & $0.0188(0.00)$ & $0.3012(0.00)$ & $0.0071(0.00)$ & $245.176(0.00)$ & 0.24 \\
\hline 5 & $0.0187(0.00)$ & $0.2177(0.00)$ & $0.0043(0.00)$ & $241.776(0.00)$ & 0.21 \\
\hline
\end{tabular}

Findings of the BIST -Financial Index herd behavior are presented in Table II. According to non-Linear model results, coefficient $\alpha$ is positive and statistical in all equations. In addition, the coefficient of the linear term $R_{m, t}$ is positive and significant for all the equations. Therefore, it can be say that CSAD increases together with $R_{m, t}$. $F$ statistics of models are significant at $\% 1$ level. Considering the shares in the financial index, existence of herd behavior effect can be seen at $\gamma_{2}$ forecasts. In general, and first periods, the sign of the parameter estimation is compatible with expectations but it is statistically insignificant. Whereas in the II. period the coefficient was positive. On the other hand, in the all periods $\gamma_{2}$ signs are seen in the same direction as the theoretical expectations and statistically significant. Mathematical predictions of the parameters predicted in the emerging markets. The size also supports that herd behavior is effective in these markets. C-H Model findings indicate that rational pricing models are still valid.

Table 3: BIST Industrial Index Herd Findings

\begin{tabular}{|c|l|l|l|l|l|}
\hline \multicolumn{7}{|c|}{ BORSA ISTANBUL 100 Industrial Index 1998-2016 } \\
\hline MODEL & $\alpha$ & $\gamma_{1}$ & $\gamma_{2}$ & F Statistic & $R^{2}$ \\
\hline 1 & $0.0171(0.00)$ & $0.0154(0.00)$ & $-0.899(0.00)$ & $411.143(0.00)$ & 0.400 \\
\hline 2 & $0.0145(0.00)$ & $0.0176(0.00)$ & $-1.404(0.00)$ & $341.246(0.00)$ & 0.311 \\
\hline 3 & $0.0173(0.00)$ & $0.0167(0.00)$ & $-0.635(0.00)$ & $653.125(0.00)$ & 0.158 \\
\hline 4 & $0.0170(0.00)$ & $0.0178(0.00)$ & $0.210(0.00)$ & $623.111(0.00)$ & 0.132 \\
\hline 5 & $0.0168(0.00)$ & $0.0179(0.00)$ & $0.156(0.00)$ & $411.754(0.00)$ & 0.144 \\
\hline
\end{tabular}




\begin{tabular}{|c|l|l|l|l|l|}
\hline \multicolumn{7}{|c|}{ 1.TERM (1998-2005) } \\
\hline 1 & $0.0177(0.00)$ & $0.331(0.00)$ & $-0.6114(0.00)$ & $561.143(0.00)$ & 0.38 \\
\hline 2 & $0.0165(0.00)$ & $0.3542(0.00)$ & $-0.924(0.00)$ & $312.154(0.00)$ & 0.29 \\
\hline 3 & $0.0186(0.00)$ & $0.2253(0.00)$ & $-0.8718(0.00)$ & $564.122(0.00)$ & 0.31 \\
\hline 4 & $0.0405(0.00)$ & $0.2152(0.00)$ & $0.0132(0.00)$ & $411.412(0.00)$ & 0.28 \\
\hline 5 & $0.05312(0.00)$ & $0.0158(0.00)$ & $0.0412(0.00)$ & $500.134(0.00)$ & 0.20 \\
\hline & & $2 . T E R M(2006-2016)$ & & \\
\hline 1 & $0.0428(0.00)$ & $0.0144(0.00)$ & $0.421(0.00)$ & $341.551(0.00)$ & 0.16 \\
\hline 2 & $0.05312(0.00)$ & $0.0177(0.00)$ & $0.154(0.00)$ & $299.098(0.00)$ & 0.12 \\
\hline 3 & $0.0196(0.00)$ & $0.0137(0.00)$ & $0.0012(0.00)$ & $341.899(0.00)$ & 0.20 \\
\hline 4 & $0.0164(0.00)$ & $0.3036(0.00)$ & $0.0071(0.00)$ & $245.176(0.00)$ & 0.20 \\
\hline 5 & $0.0188(0.00)$ & $0.2177(0.00)$ & $0.0043(0.00)$ & $241.776(0.00)$ & 0.21 \\
\hline
\end{tabular}

Analysis findings conducted on ISE-Industrial Index are included in Table 3. Data is monitored to show parallelism with ISE-All index. When CCK model is taken as basis, the influence of herd behavior in market conditions can be mentioned in the generally and first period. In addition, it was seen that the effect was abandoned in the second period. Parameter of $\alpha$ is positive and significant for the all equations as expectations. While the coefficient of $\left|R_{m, t}\right|$ is positive and meaningful for all equation, cross-sectional absolute deviation (CSAD) and $\left|R_{m, t}\right|$ increase together.

Herd behavior data is analyzed with respect to the $\mathrm{C}-\mathrm{H}$ model by considering 4 and 5 , it is understood that findings are compatible with the literature.

Table 4: Most Liquid 10 Stock Herd Findings in Borsa İstanbul

\begin{tabular}{|c|l|l|l|l|l|}
\hline \multicolumn{6}{|c|}{ BORSA ISTANBUL Most Liquid 10 Stock Herd Findings ${ }^{1}$} \\
\hline MODEL & $\alpha$ & $\gamma_{1}$ & $\gamma_{2}$ & F Statistic & $R^{2}$ \\
\hline 1 & $0.0112(0.00)$ & $0.0165(0.00)$ & $-0.789(0.00)$ & $411.143(0.00)$ & 0.400 \\
\hline 2 & $0.0111(0.00)$ & $0.0154(0.00)$ & $-1.314(0.00)$ & $341.246(0.00)$ & 0.311 \\
\hline 3 & $0.0163(0.00)$ & $0.0146(0.00)$ & $-0.423(0.00)$ & $653.125(0.00)$ & 0.158 \\
\hline 4 & $0.0174(0.00)$ & $0.0174(0.00)$ & $0.210(0.00)$ & $623.111(0.00)$ & 0.132 \\
\hline 5 & $0.0142(0.00)$ & $0.0179(0.00)$ & $0.156(0.00)$ & $411.754(0.00)$ & 0.144 \\
\hline
\end{tabular}

\footnotetext{
${ }^{1}$ Selectedsharesare Şişecam (sise), Migros (mgros), Ereğli (Eregl), Türk Hava Yolları (THY), İşbankası C (Isctr), Tüpraş (Tuprs), Koç Holding (Kchol), Arçelik (Arclk), Garanti Bankası (Garan), Akbank (Akbnk)
} 


\begin{tabular}{|c|l|l|l|l|l|}
\hline \multicolumn{7}{|c|}{ 1.TERM (1998-2005) } \\
\hline 1 & $0.0141(0.00)$ & $0.214(0.00)$ & $-0.6114(0.00)$ & $561.143(0.00)$ & 0.38 \\
\hline 2 & $0.0144(0.00)$ & $0.3382(0.00)$ & $-0.924(0.00)$ & $312.154(0.00)$ & 0.29 \\
\hline 3 & $0.0178(0.00)$ & $0.2132(0.00)$ & $-0.8718(0.00)$ & $564.122(0.00)$ & 0.31 \\
\hline 4 & $0.0311(0.00)$ & $0.3452(0.00)$ & $0.0132(0.00)$ & $411.412(0.00)$ & 0.28 \\
\hline 5 & $0.05312(0.00)$ & $0.0160(0.00)$ & $0.0412(0.00)$ & $500.134(0.00)$ & 0.20 \\
\hline & & $2 . T E R M(2006-2016)$ & & \\
\hline 1 & $0.0311(0.00)$ & $0.0211(0.00)$ & $0.421(0.00)$ & $341.551(0.00)$ & 0.16 \\
\hline 2 & $0.05412(0.00)$ & $0.0287(0.00)$ & $0.154(0.00)$ & $299.098(0.00)$ & 0.12 \\
\hline 3 & $0.0186(0.00)$ & $0.0137(0.00)$ & $0.0012(0.00)$ & $341.899(0.00)$ & 0.20 \\
\hline 4 & $0.0177(0.00)$ & $0.3036(0.00)$ & $0.0071(0.00)$ & $245.176(0.00)$ & 0.20 \\
\hline 5 & $0.0190(0.00)$ & $0.2177(0.00)$ & $0.0043(0.00)$ & $241.776(0.00)$ & 0.21 \\
\hline
\end{tabular}

In table 4, during the period of 1998-2016,minimum 5000 lots portfolio has been formed with the 10 most liquid shares traded at Borsa Istanbul. Then existence of herd behavior effect for the portfolio formed by 10 most liquid shares was examined. Findings can be seen from Table 4. According table 4, it is reached the same direction result with financial index.

In all periods when the market is in a rising trend,behavior has been observed. In the falling market, it can be shown among the analysis findings that the effect is not seen.Mathematical size of the parameter estimation in the emerging market conditions for 2. Term is High and at $1 \%$ level as in the findings of the ISE-Services Index that means $\mathrm{C}-\mathrm{H}$ model coefficient estimates do not support herd behavior.

\section{Conclusion}

It is commonly accepted that although some individual factors might affect irrational decisions, social groups have significant role. If an individual change their decisions and follows the majority due to ideas of social group they belong to, there occurs herd behavior.This paper investigates the existence of herd behavior effect in Borsa Istanbul through Christie and Huang (1995), Chang, Cheng and Khorana (2000) methodology. Most of the studies examining the empirical evidenceon herding and its effects have been done inthe context of developed countries. As a parallel of this reality, This paper has contributed in providing additional research on herding in the developing countries.

For this purpose, 2 different ways to measure of dispersion to the identify herding behavior considered the cross-sectional standard deviation (CSSD) and cross- 
sectional absolute deviation (CSAD). When the research findings are evaluated, it can be said that the effect has emerged in more developing markets, which is theoretically compatible with expectations. The reasons why developing countries face the herd behavior effect are the low number of total market participants, the low transaction volume, the problems of the foreign investors entering the country for speculative purposes.

In the empirical part of study, herd behavior effect in Borsa İstanbul was examined by using Borsa Istanbul 100 Index, BorsalstanbulFinancal Index, BIST Industrial Index and minimum 5000 lots portfolio has been formed with the 10 most liquid shares traded at Borsa İstanbul. It was detected that the herd behavior effect was seen in all.

It supports the presence of the effect on the findings of rising and falling markets that express the financial pressure environment.

The parameters of the regression equation estimated for Term 1 (1998-2005) show that the effect of herd behavior on rising markets, but with the same effect does not exist in the bear markets. The results are compatible with the study of Kayalidere (2012). C-H (1995). Our result is compatible with the idea that market participants demonstrate herding behavior around an indicator like an index displaying a common behavior of allmarket components when there exist relatively expansive and "positive" fluctuationsand that it leads up to a non-linear relationship between CSAD and average marketreturns. The market has a relatively deeper and more efficient market that the findings of the period of 2005-2012 supported this idea. While there is no effect on the portfolios of Borsa Istanbul 100 Index and Borsa Istanbul Industry Index, herd behavior on the Borsa Istanbul Financial Index and the most liquid 10 stock portfolios was observed only the emerging market. In the term II, herd in the literature with the findings that the effect of behavior was observed especially at emerging markets, it is possible to compare the results of the Borsa Istanbul with the end of the 1990 s and the beginning of the 2000s was supported by the idea that it was a deeper market. Finally, despite intensive herding behavior experienced at the first sub-period, result of limited herding at the second sub-period show the rise of diversification opportunities.

\section{References}

Ohlson, P. (2010). "Herd Behavior on the Swedish Stock Exchange", Jönköping International Business School. Master Thesis in Finance.

Demirer, R., Kutan, A M. ve Chen Chun-Da (2010). "Do Investors Herd in emerging Stock Markets?: Evidence from the Taiwanese Market", Journal of Economic Behavior\&Organization. 76: 283295.

My, T. N., Truong, H. H., (2011). "Herding behavior in an emerging stock market: Empirical evidence from Vietnam", Research Journal of Business Management, Vol. 5, No. 2, 51-76

Christie , W. G. and Huang, R. D. (1995). "Following the Pied Piper: Do Individual Returns Herd around the Market?", Financial Analysts Journal. July-August: 31-37.

Bikhchandani, S. and Sharma, S. (2001), "Herd Behavior in Financial Markets" IMF Staff Papers 47(3), 279-310. 
Lakonishok, J., Shleifer, A. veVishny, R., W. (1992). "The Impact of Institutional Trading on Stock Prices". Journal of Financial Economics. 32, 23-43.

Chang, E. C. ,Cheng, J. W. ve Khorana, A. (2000), " An Examination of HerdBehavior in EquityMarkets: An International Perspective", Journal of Bankingand Finance, 24:1651-1679.

Hwang, S. ve Salmon, M. (2004). "Market StressandHerding", Journal of Empirical Finance.11, 585616.

Christie, W. G. ve Huang, R., D.; (1995), "FollowingthePiedPiper: Do IndividualReturnsHerdaroundthe Market?", Financial AnalystsJournal. July-August: 31-37.

Chang, E., Cheng, J. and A. Khorana. (2000). "An examination of herdbehavior in equitymarkets: an internationalperspective",Journal of Bankingand Finance, 24(10), 1651-1679.

Güvercin, A.(2016). "SentimentalHerding: The Role of Regionaland Global Shocks in EgyptianandSaudiStockMarkets, Sosyoekonomi", Vol.24(27),25-32.

Kayalıdere,K (2012). "Hisse Senedi Piyasasında Sürü Davranışı: IMKB'de Ampirik Bir İnceleme", İşletme Araştırmaları Dergisi”, 4/4, 77-94.

Kapusuzoğlu,A. (2011). "Herding in thelstanbulStock Exchange (ISE): A case of behavioralfinance" can journal of businessmanagement 5(27), 15-26.

Solakoglu, N. and Demir, N. (2014). "Sentimentalherding in Borsa Istanbul: informedversusuninformed", AppliedEconomicsLetters, 21, 14, pp. 965-968. 